Florida International University FIU Digital Commons

$11-5-2015$

\title{
Hospitality Education Assessment: A Case Study on the Learning Experience of Chinese Students in a 4-year Program at a U.S. Institution
}

Rossy Ambe-Cohen

Florida International University, rambe002@fiu.edu

DOI: 10.25148 /etd.FIDC000192

Follow this and additional works at: https://digitalcommons.fiu.edu/etd

Part of the Bilingual, Multilingual, and Multicultural Education Commons, Educational Assessment, Evaluation, and Research Commons, and the International and Comparative Education Commons

\section{Recommended Citation}

Ambe-Cohen, Rossy, "Hospitality Education Assessment: A Case Study on the Learning Experience of Chinese Students in a 4-year Program at a U.S. Institution" (2015). FIU Electronic Theses and Dissertations. 2296.

https://digitalcommons.fiu.edu/etd/2296 


\section{FLORIDA INTERNATIONAL UNIVERSITY}

Miami, Florida

\section{HOSPITALITY EDUCATION ASSESSMENT: A CASE STUDY ON THE \\ LEARNING EXPERIENCE OF CHINESE STUDENTS IN A 4-YEAR PROGRAM AT \\ A U.S. INSTITUTION}

A thesis submitted in partial fulfillment of the

requirements of the degree of

MASTER OF SCIENCE

in

HOSPITALITY MANAGEMENT

by

Rossy Ambe-Cohen

2015 
To: Dean Mike Hampton

School of Hospitality and Tourism Management

This thesis, written by Rossy Ambe-Cohen, and entitled Hospitality Education Assessment: A Case Study on the Learning Experience of Chinese Students in a 4-year Program at a U.S. Institution, having been approved in respect to style and intellectual content, is referred to you for judgment.

We have read this thesis and recommend that it be approved.

$\begin{array}{r}\hline \text { Miranda Kitterlin } \\ \hline \text { Mary L. Tanke } \\ \hline \text { Carolin Lusby, Major Professor }\end{array}$

Date of Defense: November 5, 2015

The thesis of Rossy Ambe-Cohen is approved.

Dean Mike Hampton School of Hospitality and Tourism Management

Dean Lakshmi N. Reddi University Graduate School

Florida International University, 2015 


\section{ACKNOWLEDGMENTS}

This thesis would not have been possible without the guidance and support of several individuals who contributed and extended their assistance and encouragement in the preparation and completion of this study.

First and foremost, my deepest gratitude to my thesis chair, Dr. Carolin Lusby without whom this study would not have been possible. Dr. Lusby has been an inspiration during this time and I am thankful for her support, insights and commitment to my education.

Secondly, I would like to share my appreciation for my committee members, Dr. Miranda Kitterlin and Dr. Mary L. Tanke for all the time and energy they have devoted to my thesis. They are both industry experts and role models in my professional career.

Thirdly, I would like to thank my mentor Judith Williams, her kind words of support and encouragement have not only helped me finish this thesis but working as her Teaching Assistant has been a learning experience unlike any other. I am privileged to call her a friend and mentor.

Lastly, I would like to thank all of my participants for their willingness to help in this study and sharing their experiences with me. I would also like to thank the Chaplin School of Hospitality and Tourism Management for making this study possible. 


\author{
ABSTRACT OF THE THESIS \\ A U.S. INSTITUTION \\ by \\ Rossy Ambe-Cohen \\ Florida International University, 2015 \\ Miami, Florida \\ Professor Carolin Lusby, Major Professor
}

HOSPITALITY EDUCATION ASSESSMENT: A CASE STUDY ON THE

LEARNING EXPERIENCE OF CHINESE STUDENTS IN A 4-YEAR PROGRAM AT

The purpose of this study was to investigate the learning experience of Chinese hospitality students in a 4-year program at a U.S. institution in order to bridge the gap between Chinese and American education. This study could challenge traditional education and produce more culturally savvy and diverse graduates, in a field as personal and interactive as Hospitality Management, it could also help American students who want to study, work or teach in China, as they would be knowledgeable of the cultural and educational differences. This study used a qualitative approach. The researcher conducted in-depth, semi-structured interviews with Chinese hospitality students in a 4year program at a U.S. institution based on the research questions presented regarding the perceived differences in learning experiences of Chinese Hospitality students. Findings of this study could have implications for the hospitality industry and more importantly the way hospitality education is being taught in a 4-year program at a U.S. institution. 
CHAPTER I: INTRODUCTION ERROR! BOOKMARK NOT DEFINED. STATEMENT OF THE PROBLEM ERROR! BOOKMARK NOT DEFINED. STATEMENT OF PURPOSE ERROR! BOOKMARK NOT DEFINED. RESEARCH QUESTIONS... ERROR! BOOKMARK NOT DEFINED. DEFINITION OF TERMS ERROR! BOOKMARK NOT DEFINED. DELIMITATIONS ERROR! BOOKMARK NOT DEFINED. LIMITATIONS. ERROR! BOOKMARK NOT DEFINED. ASSUMPTIONS ERROR! BOOKMARK NOT DEFINED. IMPORTANCE OF THE STUDY ERROR! BOOKMARK NOT DEFINED.

CHAPTER II: LITERATURE REVIEW ERROR! BOOKMARK NOT DEFINED. CULTURE ERROR! BOOKMARK NOT DEFINED. TEACHING MODELS. ERROR! BOOKMARK NOT DEFINED. MOTIVATIONS ERROR! BOOKMARK NOT DEFINED. SUMMARY OF LITERATURE ERROR! BOOKMARK NOT DEFINED.

CHAPTER III: METHODOLOGY ERROR! BOOKMARK NOT DEFINED. POPULATION AND SAMPLE SELECTION. ERROR! BOOKMARK NOT DEFINED. DATA COLLECTION PROCEDURES ERROR! BOOKMARK NOT DEFINED. RELIABILITY AND VALIDITY ERROR! BOOKMARK NOT DEFINED.

CHAPTER IV: FINDINGS ERROR! BOOKMARK NOT DEFINED. DATA COLLECTION AND PARTICIPANT POPULATION ...ERROR! BOOKMARK NOT DEFINED. LANGUAGE ERROR! BOOKMARK NOT DEFINED. VALUE OF EDUCATION ERROR! BOOKMARK NOT DEFINED. SOCIAL SKILLS AND COMMUNICATION ERROR! BOOKMARK NOT DEFINED. WORK EXPERIENCE AND LEGAL ISSUES. ERROR! BOOKMARK NOT DEFINED. SUMMARY.... ERROR! BOOKMARK NOT DEFINED. 
CHAPTER V: CONCLUSIONS AND IMPLICATIONS ERROR! BOOKMARK NOT DEFINED.

STUDY FINDINGS ....................................................ERROR! BOOKMARK NOT DEFINED. IMPLICATIONS ........................................................ERROR! BOOKMARK NOT DEFINED. LIMITATIONS AND RECOMMENDATIONS FOR FUTURE STUDYERROR! BOOKMARK NOT DEFINED.

REFERENCES ERROR! BOOKMARK NOT DEFINED.

APPENDICES ERROR! BOOKMARK NOT DEFINED. 


\section{CHAPTER ONE}

\section{INTRODUCTION}

Current research has shown that there are many cultural, philosophical and political differences between the Chinese and American ethnic groups. However, it is very important that there is research done to bridge the gap between the ethnic characteristics in order to not only understand how Chinese students think and what their cultural values are but also how to adapt our American cultural values and perceptions in order to teach, work with, and manage not only Chinese students but also American students in the hospitality industry. Through this research study, the researcher attempted to collect information on the learning experience of Chinese hospitality students in a 4year program at a U.S. institution and help create a new curriculum to better serve hospitality students and the hospitality industry. The purpose of this study was to investigate and compare the learning experience of Chinese Hospitality students in a 4year program at a U.S. institution in order to create a curriculum that would help bridge the gap between Chinese and American education. The qualitative study was based on interviews from current Chinese hospitality students to learn about their views on their perceived learning and the quality of their learning and to examine and issues that may emerge from those answers.

This research paper answered the question of how exactly does Chinese learning experiences differ from those of American students. Some current opinions regarding Chinese learning experiences are those of Raymond Ho, who writes that "Chinese students are rote and passive learners” (Ho, 2012, p.161). According to Hammond and 
Gao, “contemporary Chinese education is characterized by memorization, rote learning and repetition,” (Hammond \& Gao, 2002), and Thakkar, “Chinese learners emphasize effort over ability” (Thakkar, 2011).

These reasons combined with the idea that we are in a globalized world and the hospitality industry is a service based industry with human qualities, make it very important for research to be done in order to improve the teaching methodology and therefore learning experience of Chinese students as well as American students.

\section{Statement of the Problem}

There is current research on learning experiences, cultural differences and motivations of Chinese students in the U.S. However, there is limited research on how to create a curriculum that can both integrate Chinese students to American education in a way that maximizes their potential as well as give American students a culturally diverse education which will help them deal with the global world and the hospitality industry. Research is necessary, especially in the field of Hospitality Management to assess how to bridge the gap between the Chinese and the American students. It is important for Chinese students to feel more comfortable with the open, communicative American teaching style as well as give American students a better understanding of the Chinese formal teaching style which can prove to be helpful and necessary when Chinese and American students are working together so they can both understand each other's cultures and attitudes better. Chinese students learn based on their culture and values so it is important that they can be taught appropriately given that the Hospitality industry is based on personal service in a global field and Chinese students differ not only in their cultural and philosophical values, but also in their learning styles, compared to their 
American counterparts. Creating a curriculum to meet both the Chinese and the American students' needs is not only important it is necessary due to the interactive nature of the Hospitality industry but also of the globalized world we live in.

\section{Statement of Purpose}

The purpose of this study was to investigate and compare the learning experience of Chinese hospitality students in a 4-year program at a U.S. institution in order to create a curriculum that could help bridge the gap between Chinese and American education. The qualitative study was based on interviews from current Chinese Hospitality students to learn about their views on their perceived learning and the quality of their learning and to examine and issues that may emerge from those answers.

\section{Research Questions}

The overall research question investigated the learning experiences of Chinese hospitality students in a 4-year program at a U.S. institution.

\section{The following questions were created for this study:}

1. What is Chinese students perception of their learning experience?

2. What do Chinese students feel is missing from their learning experience?

3. What is Chinese students perception of their American counterparts?

Keywords: learning experience, Chinese students, American students, hospitality industry.

\section{Definition of Terms}

For the purpose of this study, the following definitions were used. 
Learning experience: The Glossary of Education Reform defines learning experience as, “any interaction, course, program or other experience in which learning takes place” (Glossary, 2013). Learning experience also refers to student’s “perceptions of their learning environment” as well as what they believe they are learning and their workload, (Trigwell, Ashwin \& Millan, 2013).

Chinese students: For the purpose of this research project we defined Chinese students as Chinese nationals studying in the United States, specifically those in a 4-year Hospitality program.

American students: For the purpose of this research project we defined American students as those born in the American continent, who have Western values.

Hospitality industry: Once again, we defined the Hospitality industry according to the definition from the Oxford dictionary as "the hotel and catering industry; ...the provision of accommodation, food and beverages” (Oxford, 2013). However, the hospitality industry also includes Travel and Tourism, which are such an important part of living and working in South Florida.

Culture: Culture is defined by Merriam-Webster as "the beliefs, customs, arts, etc., of a particular society, group, place, or time” (2015). For this project, culture referred to Chinese culture and its differences from American culture.

Motivations: According to Deci and Ryan, motivation is "to be moved to do something” (Deci \& Ryan, 1985). There are two types of motivations, intrinsic and extrinsic. Intrinsic motivation comes from the inner self, doing something because we want to. Extrinsic motivation comes from the expectation of a given outcome. 
Affiliated Schools: A formal partnership between colleges or universities to send, and/or receive students from one school to an affiliated partner.

\section{Delimitations}

This study was delimited by time and location for data collection. Data was collected during a two-week period, starting on August 27, 2015 and ending on September $10^{\text {th }}$, 2015. The data collection for this study focused on Chinese Hospitality Students in a 4-year program at a U.S. institution. Interviews were conducted in English. Only a portion of the student population was sampled.

\section{Limitations}

Although the research for this study was carefully prepared, there were some limitations. This study was limited to students from a single Department in one university. The interviews were conducted in English, which could present problems with interpretation. Data collection was restricted to participants who chose to partake in the interviews.

\section{Assumptions}

The researcher made the following assumptions: (1) The interview created specifically for this study was designed appropriately to determine the perception on their learning experience and learning process. (2) All participants answered the questions honestly, reliably and without any prejudice.

\section{Importance of the Study}

This study is important because it investigates and compares the learning experiences between Chinese and American students in a 4-year program at a U.S. 
institution. This could help assess the quality of Hospitality education Chinese students are receiving, pinpoint the gaps in understanding and make way for a new curriculum to help fill these gaps. As we have previously stated, there is current research regarding the learning differences in Chinese and American students, however, there is a lack of research regarding how to best handle these differences in order to consistently teach both Chinese and American students in a way that makes sense for both and maximizes their potential. Therefore producing culturally savvy graduates who can study and work not only in America but also in China and are better prepared to serve the global needs of the hospitality industry. This research topic is important given not only the nature of the hospitality industry, a service based industry, but the increasing number of Chinese students coming to study in the United States according to Huang (2012). Another reason this study is important is because given the increasing popularity of Hospitality Management as a subject and many schools capitalizing on this popularity, it is imperative that we are aware of what these students are being taught not only in the United States campuses but also abroad, as some schools currently offer study abroad opportunities to different countries. Being able to understand and gain knowledge on Chinese students learning experience and how to apply these differences into a uniform, consistent curriculum to teach both Chinese and American students based on their cultural and philosophical values while studying Hospitality in the United States, will help to create a better understanding on what steps need to be taken to help students achieve their full potential and produce well rounded graduates. 


\section{CHAPTER TWO}

\section{LITERATURE REVIEW}

The purpose and goal of this study was to investigate and compare the perceived learning experience of Chinese hospitality students in a 4-year program at a U.S. institution in order to come up with a new curriculum to better serve both Chinese and American students. Previous research has mostly been concentrated on case studies and it has focused on either business students or Science and Math students and while it defines learning differences in Chinese students compared to their American counterparts, it does not come up with a solution to fix this issue. It is helpful to analyze these case studies and the available research in order to see not only what the findings are but also where the gaps are. As the hospitality industry continues to grow, and more Hospitality management courses are being offered, it is very important that we examine the hospitality industry and the way it is being taught in the United States, specifically in a 4year program. This will not only give us a greater awareness of the changes needed in order to not only grow a better industry but to fix the current problems from the inside, teaching future industry professionals what is missing and what needs to change in the globalized world we are living in.

This study covered three areas of Chinese education in the United States and why they are different from Chinese education in China. The first section covered Culture. The second section covered Teaching Methods and the third section covered Motivations. 


\section{Culture}

The reason culture was being explored in this study is because one cannot define the learning experiences and learning processes of Chinese students if we have not defined who Chinese students are and what makes them different from American students. Chinese culture is based on three major religions: Confucianism, Taoism and Buddhism. Confucianism is based on the philosophy of Confucius, a government official who believed a "good government” with "good officials" was the way to instill morals and live at peace. It is based on the idea that Chinese must have a "harmonious spirit" and must “emphasize unity” (Guang, 306).

Taoism is based on the philosophy of Lao-tzu, who believed in "the way". The aim of Taoism is to have a relationship to the Tao, a "unifying, unnamed and unknowable source” (PSU). Neither Confucianism nor Taoism deal with the concept of individual responsibility.

Buddhism is based on the philosophy of Buddha, who believed that what we do in this world will affect what happens to us in the next, and how we are reborn, a concept known as "Karma”, which is based on individual responsibility (Guang, 312).

All three religions aim to enlighten the mind, body and spirit of the person and therefore create enlightened, moral societies. This shows that simply based on the three major religions in China, Chinese are not egocentric, they will act morally for what will help the society as a whole. 


\section{Teaching Models}

Due to the influence of Confucianism and a "social context that promote obedience and discourages creativity” (Holmes, 2004), it is very difficult for Chinese students to be critical thinkers when they are used to an obedience model. Therefore, it is important to be aware of different teaching models so we understand how each one can affect students and which model is used in China vs America.

Based on the literature, "teaching models can be divided into five patterns" (Grasha, 2002). The "Expert” is one whose model is teacher based, uses "teachercentered questioning and discussion” and expects dependent learners. He does not available for questions or discussions outside of the classroom. The "Formal Authority" does not have the knowledge of the "Expert", so he "establishes standards and goals". He also uses a teacher-centered model and also expects dependent learners but he also expects some participation and gives some feedback. The "Personal Model” is neither teacher-centered nor student center, it uses a teacher-centered approach but expects participative and collaborative learners. The "Facilitator" is a teaching model that is student-centered and is based on critical thinking, problem-based learning and expects collaborative and independent learners. Finally, The "Delegator” is a completely studentcentered model based on small group discussions, independent study, and who expects independent, participative learners. The "Delegator" is available to his students outside of class (Grasha, 2002). The importance of examining these teaching models is to see the difference in teaching styles and where we can clearly see that according to what we know about Chinese culture, Chinese Professors are closely related to either The “Expert” or The "Formal Authority” teaching models, whereas American Professors are 
closely related to either The "Facilitator" or The "Delegator" which makes it difficult for Chinese students to transition from one model to the other one (Huang, 2012, p. 141). “Chinese students prefer the teacher-centered teaching methodology” (Ho, 2012, p.172). According to Durkin, "traditional teaching styles in Chinese institutions were teachercentered and exam-based” (Durkin, 2011).

\section{Motivations}

Chinese "learning styles...family influence and social attitude toward failure differ greatly from the Western learners” (Ho, 2012, p. 162). Chinese students in the United States can be "uncomfortable with activities like participating in group discussions... and critical argumentations” (Durkin, 2011). This goes back to their culture and the teaching models they are used to.

Another point the literature is clear on is the idea of intrinsic vs extrinsic motivation. As the literature explains, some of the major differences between Chinese and American students are based on cultural differences. However, this also means that their motivations for learning may be different. For example, if we explore the Chinese concept of "self", we see that it is an "interdependent concept of self", which is completely different from that of the American concept of "self” (Wang, 2012, p.77). What this means is that due to Cultural traditions, the need for autonomy has been repressed for the greater good of their society. Therefore, it is difficult for them to be competitive and act independently because they are used to acting for the benefit of their communities and societies instead of their individual benefit (Lin, Ho \& Lin, 2013, p 97). 
There is a common saying that will clearly show us part of their motivation, especially for studying. "Who you are is more important that what you know", this means as long as you have the right connections, you will be fine regardless of your expertise (Wang, 2012, p.80). This concept may be very difficult for Americans to understand because especially in the U.S., experience and educations are what matters most, not connections. However, we must understand that Chinese students in the U.S. are not only in a foreign country, they are also dealing with "a lack of work experiences and career development opportunities”, because in China they are not expected to work until they have finished their education so they come here to study and their American classmates have usually been in the job market for years, even if not in their desired field (Huang, 2012, 142).

Motivations also differ because Chinese students study because of the intrinsic motivation of acquiring knowledge, it is part of their moral compass, as is working, which is why stereotypically, Chinese people are seen as hardworking people (Lin, Ho \& Lin, 2013, p 101). They are studying to gain knowledge, whereas American students tend to be extrinsically motivated and are studying to earn a grade ( Huang, 2012, 139). 


\section{Summary of Literature}

Primarily research on learning experiences of Chinese students in the U.S. deals with students in Science and Math. This research examined the cultural differences, teaching models and motivations that differentiate Chinese students from their American counterparts. It is important to understand the impact of these differences in order to assess how Hospitality education is being taught in a 4-year program at a U.S. institution and make way for a new curriculum if necessary to encompass these differences and create well rounded graduates no matter their ethnicity or cultural background. There is current research on learning experiences, cultural differences and motivations of Chinese students in the U.S. However, there is limited research on how to deal to create a curriculum that can both integrate Chinese students to American education in a way that maximizes their potential as well as give American students a culturally diverse education which will help them deal with the global world and the hospitality industry. Through this research study, the researcher collected information on the learning experience of Chinese hospitality students in a 4-year program at a U.S. institution and help create a new curriculum to better serve Hospitality students and the hospitality industry. 


\section{CHAPTER THREE}

\section{METHODOLOGY}

This study conducted research to better understand the learning experience of Chinese hospitality students in the United States. The researcher was unable to find any literature and previous studies on how to integrate the learning differences of Chinese hospitality students in the United States into a curriculum that bridges the gap between Chinese and American learning experiences. The lack of data available created a need for a study in this area. A qualitative study helped to measure the various perceptions of Chinese hospitality students in a 4-year program at a U.S. institution in order to assess their education, find the gaps and create a new curriculum to bridge the gaps in Chinese and American learning experiences. To measure their learning perceptions, in-depth semi-structured interviews with snowball sampling were conducted and grounded theory was used as a data analysis method. All participants were Chinese hospitality students from a 4-year program at a U.S. institution. Some students were part of an affiliated program and some had enrolled independently from any affiliations.

\section{Grounded Theory Approach}

This research method was chosen because it allows the researcher to hypothesize what is happening and then allows them to verify it (Charmaz, 2007). According to Glaser and Strauss, following the steps in the data analysis process allows researchers to understand patterns and themes from the participants' perspectives. There are three parts to the coding process: open, axial and selective.

In the first step, open coding, the researcher reads the data over and over, therefore increasing her adeptness to identify, label, and name. The next step is axial 
coding, the process of relating the different codes or categories to each other. Finally, in selective coding, the researcher selects one core category and describes how all of the categories are related. Glaser and Strauss state that it is essential that the researcher use constant comparison while reviewing the interviews.

\section{Population and Sample Selection}

Population sample was based on gathering sufficient participants to reach maximum saturation on the subjects dealing with learning experience and learning process of Chinese hospitality students in a 4-year program at a U.S. institution. This study used purposive sampling, such as snowball sampling with maximum variation. Snowball sampling means that the researcher requests each participant to suggest additional people to interview (Babbie, 2002). The sample is a non-probability sample. Sampling is completed when adding one more participant to the sample does not add any new information.

All participants were Chinese hospitality students from a 4-year program at a U.S. institution and had been enrolled for at least one semester previous to being interviewed, some were part of an affiliated program and some enrolled independently.

A verbal announcement (see Appendix C) briefly describing the study and requesting volunteers was made at the Chaplin School of Hospitality and Tourism Management to all Chinese students. Those who wished to take part in the study were to

contact the researcher directly. The responders to the verbal announcement were provided with additional information and instructions as to what would be needed from them. An interview appointment was made with each participant for a mutually convenient location and time. Interview questions and a Consent-to-Participate Form were distributed at the 
time of the interview. Interviews were then conducted over a two-week period.

\section{Data Collection Procedures}

The data process began with individual semi-structured interviews with open ended questions, which allowed each participant to share his or her experiences freely. According to Beck (2004, p.204), "semi-structured interviews are intended to generate interviewees’ accounts of their own perspectives, perceptions, experiences, understandings, interpretations, and interactions.” Grounded theory, therefore, was used to recognize and compare the emerging patterns of each individual.

The interviews consisted of three types of questions: introductory questions, follow-up questions, and probing questions. Introductory questions were open ended questions which allowed each participant to share his or her experiences freely. Follow up questions allowed them to elaborate on the introductory questions and probing questions asked for more details as to why their experiences were what they were (Kvale, 1996).

The interviews were conducted at a 4-year hospitality management program at a U.S. institution. A verbal announcement was given inviting students to participate and an in-depth description of the study was provided to participants. The purpose of this study was reiterated at the time of the interview as well as when collecting signed consent forms.

The interviews were audio recorded for the purposes of transcription and data analysis. In addition to audio recording, detailed notes were taken in order to provide key 
concepts, which could be lost on an audiotape, e.g., body language, expressions, and demeanor. Finally, the interview was transcribed verbatim into a Microsoft Word file upon completion, assigning each transcript a pseudonym in the process.

Participants were contacted after the interpretation of results in order to make sure their answers had been properly interpreted to make sure there are no issues with translation or interpretation.

\section{Reliability and Validity}

In research studies it is important to establish trustworthiness and creditability, which is why reliability and validity are essential in establishing these factors when creating and implementing a research project. However, in qualitative research, validity and reliability are insufficient and hold little value in replicating results (Lincoln \& Guba 1985). For validity, credibility and trustworthiness may be established through transferability and triangulation.

A researcher can establish credibility through prolonged engagement and persistent observation. The researcher must stay in the field long enough to obtain a valid understanding. Lincoln and Guba believed that the reader, instead of the researcher, should decide how transferable the findings are. Through in-depth description by the researcher, the reader will be able to apply the data to his or her own situation. Another method to establish trustworthiness of data is through triangulation (Lincoln \& Guba, 1985).

Triangulation "strengthens a study by combining methods. This can mean using several kinds of methods or data, including using both quantitative and qualitative 
approaches” (Patton, 2001, p. 247). Triangulation was employed by recording the interviews, taking informal notes on mannerisms and delivery during the interview, submitting my findings to three experts in Chinese student education in the U.S. for their review and by verifying my conclusion with the research participants.

\section{Summary}

This qualitative study relied on semi structured interviews with Chinese hospitality students in a 4-year program at a U.S. institution. To measure their learning perceptions, in-depth semi-structured interviews with snowball sampling were conducted and grounded theory was used as a data analysis method. Interviews were held until saturation was achieved and no new themes emerged. Interviews were recorded, transcribed and coded by two different researchers and themes were constantly compared using the constant comparative method. 


\section{CHAPTER FOUR}

\section{FINDINGS}

The following chapter summarizes the findings and themes that emerged from the fourteen in depth semi-structured interviews with Chinese graduate and undergraduate hospitality students at a major university in the United States in order to understand their learning experiences. Each participant answered nine questions created by the researcher in order to identify Chinese hospitality students learning experiences at a major university in the United States. Interviews were held until saturation was achieved and no new themes emerged. Interviews were recorded, transcribed and coded by two different researchers and themes were constantly compared using the constant comparative method.

\section{Data Collection and Participant Population}

The participants were all Chinese hospitality management students at Florida International University, Chaplin School of Hospitality and Tourism Management in Miami, Florida. A verbal announcement briefly describing the proposed study and requesting volunteers was made at the Chaplin School of Hospitality and Tourism Management. Those who wished to participate in the study were to contact the researcher directly. Students were all Chinese nationals enrolled in the hospitality program for at least one semester previous to the interview. There was an even number of male and female participants. Nine participants were graduate students and five were undergraduate students. Eight students came from the Tianjin Campus of Florida International University, six enrolled independently from any affiliations. A total of 
fourteen people were interviewed in a two-week period. Snowball sampling was used to reach saturation.

Each interview was audio recorded and later transcribed, allowing the researcher to code and analyze the data collected. None of the interviews lasted more than 30 minutes, with 20 minutes being the average. No more than one interview was held with each participant. After the interviews, pseudonyms were given and each interviewee was able to verify the accuracy of the given information by reviewing the researcher's notes and interview guide. Only these verified transcriptions were used in the course of the study. This chapter was structured based on the four main themes that emerged from the interviews in level of importance, not the research questions. 
Table 1- Participant Demographics

\begin{tabular}{|l|l|l|l|}
\hline Participant & Gender & Enrollment Status & Affiliated Campus/ Independent Enrollment \\
\hline 1 & M & Grad & Affiliated \\
\hline 2 & F & Grad & Independent \\
\hline 3 & M & Grad & Affiliated \\
\hline 4 & M & Undergrad & Affiliated \\
\hline 5 & F & Undergrad & Independent \\
\hline 6 & F & Undergrad & Affiliated \\
\hline 7 & F & Grad & Independent \\
\hline 8 & M & Grad & Affiliated \\
\hline 9 & F & Undergrad & Independent \\
\hline 10 & F & Grad & Affiliated \\
\hline 11 & F & Grad & Independent \\
\hline 12 & M & Grad & Independent \\
\hline 13 & M & Grad & Affiliated \\
\hline 14 & M & Undergrad & Affiliated \\
\hline
\end{tabular}

Table 2- Themes

\begin{tabular}{|l|l|l|l|}
\hline Theme Number & Theme & $\begin{array}{l}\text { Code } \\
\text { Letter }\end{array}$ & Subtheme \\
\hline 1 & Language & A & Shame \\
\hline 2 & Value of Education & B & Chinese bubble, Different camps \\
\hline 3 & Social Skills & C & Public speaking, life in Miami \\
\hline 4 & $\begin{array}{l}\text { Work Experience/ Legal } \\
\text { Issues }\end{array}$ & D & Lack of work experience/ Visa \\
\hline
\end{tabular}




\section{Theme 1- Language:}

English is a challenge for most of the participants interviewed. Many expressed a need for professors to "force them" to speak in class because as part of their culture, they will do what the professor tells them to do. Seventy one percent of the students interviewed cited language as a major challenge in their education, while fifty percent talked about nervous and a dislike about working in groups and speaking in class for fear of not being understood. This became apparent to the researcher during the interviews as it was a common occurrence having to repeat or explain the interview questions to most of the participants.

\section{Subtheme 1A: Shame}

A majority of the students interviewed talked about shame and embarrassment at saying the wrong things when speaking in class or doing a presentation, especially when surrounded by other Chinese students, since shame is such a prevalent concept in their culture. So it was not so much the American professor or students that posed a constraint to speaking up, but the fear of embarrassment in front of their Chinese counterparts that hindered these students from speaking up. Supporting this argument, participant eight, a male graduate student from the affiliate program said, "Chinese students never worry about how American students thinking their answer, but Chinese students sometimes worry about how another Chinese student's thinking about their answer.” Because of the shame of being wrong but the desire to speak in class and be heard, Chinese students are in a constant state of inner conflict during their education in America. This shame and resulting inner struggle in that way is a direct result of a saturation of other Chinese 
students in the classes. This theme emerged as prevalent in all questions asked and will be discussed in more detail but is worth mentioning here as it impacts ability to speak up in class, perceived value of education and experience in America. Half of the students interviewed also said they needed more assistance with their English skills and suggested an "English corner", a space where Chinese students meet with other Chinese students as well as American students to practice their English and would like more opportunities to talk outside of class. Forty two percent said they needed language help and practice in order to work better in groups. Twenty one percent cited language difficulties as a concern in their education and fifty percent talked about feeling ill prepared to communicate with American students and do group presentations because of both the language and the cultural barrier. They feel American students and some American professors talk too fast so it is difficult for Chinese students to understand them and participate in group discussions because of it. A few students suggested that professors ask questions to students. As such, interviewee two, a female, graduate student who enrolled independently said professors should "not ask if anyone has the answer because Chinese students will not respond”, this is due not only to their shyness and their fear of being misunderstood but also due to their fear of being embarrassed. Supporting this argument, participant six, a female undergraduate student from the affiliate program said "Professors need to ... randomly select students and ask opinions, not simply those who speak best, Professor must be in control of class.” This statement really highlights the internal struggle these Chinese students face, to the point where they want to be called upon, or in other words be forced to speak so as to not have to face embarrassment of voluntarily speaking up and potentially providing a seemingly "wrong” answer. 
Sixty percent of the hospitality students coming from the affiliated university felt they needed more English courses before coming here in order to better prepare them not only to communicate with American students and Professors but to life in the U.S. They also expressed the need for a peer mentor to help them adjust not only to the American education system but to life in America. When they live in Tianjin, they have everything inside the campus, when they come here, even if they live in the dorms they "still need to know how to go a supermarket, make a call”, as participant three, a male graduate student from the affiliate program explained.

\section{Theme 2- Value of Education:}

Another main concern that came up in the interviews was the perceived value of the education Chinese hospitality students are receiving. Students expressed that they felt their education was devalued by the amount of Chinese students in the program, Subtheme 2A examines this Chinese bubble and the impact it has.

\section{Subtheme 2A-Chinese Bubble}

Seventy one percent of the students interviewed talked about having "too many Chinese students and not enough foreign students” in their program. Chinese hospitality students' motivation to come to the United States to study was not only based on their interest in hospitality, but also because they wanted to learn from different backgrounds and cultures. However, they feel that because there are so many Chinese students in the program, they can live in a "bubble" by just interacting with other Chinese students, do their internship in Chinese businesses, live in the dorms or with other Chinese students so they feel they are missing out on the diverse education they expected to receive but also on meeting and interacting with a variety of people from different countries and culture, 
which they in turn feel devalues their education as participant 7, a female graduate student who enrolled independently pointed out. The seventy one percent not only want less Chinese students per class but they also want a more diverse student body in their classes. Supporting this argument, participant 8, a male graduate student from the affiliate program stated “...difficult to interact with Americans because there’s too many Chinese, we can speak Chinese, eat at Chinese restaurants, no need to interact and learn English, this is bad.”

Fifty percent of students spoke about feeling conflicted when they are in classes with other Chinese students because on one hand they want to learn from others and speak up in class but on the other hand, they feel a duty to represent their cultural values and remain quiet, especially if they are not completely sure that what they will say is right and they might end up being embarrassed by their fellow Chinese classmates.

\section{Subtheme 2B- Chinese Camps}

Another issue regarding their education is that fifty percent of the students interviewed claimed there is not only inequality but a large gap between Chinese students who enroll independently and Chinese students who enroll as part as their affiliation with the Tianjin program. There is a misconception that students coming from the affiliate program in Tianjin pay less tuition than those who enroll independently (this is not the case). There is a lack of trust between both types of students as students who enroll independently, such as participant two, a female graduate student think students who come from Tianjin "don't have to work as hard" as them to do well in school and "they are lazy.” There is also friction between groups because students who enroll independently feel it is very difficult to interact with Tianjin students as many of them 
know each other from Tianjin and friendships have already been formed, so they feel like outsiders as participant five, a female undergraduate student who enrolled independently stated, "everyone from TUC stays with people from TUC."

There is also a concern between Chinese students that American students may not want to work with them. Participant seven, a female graduate student who enrolled independently wondered if “...non-Chinese students willing to cooperate with Chinese students to work in groups and for projects?” This is a concern for them because Chinese students would like to interact with American students but they feel shy and misunderstood so they are unsure that American students will want to work with them, which hurts their confidence and doesn't let them enjoy their educational experience or their time in America.

\section{Theme 3- Social Skills and Communication:}

Fifty seven percent of Chinese students interviewed stated that they needed help with social skills. Many of them, such as participant four, a male undergraduate student from the affiliate program referenced an "English corner" as a way for them to not only practice their English but interact with American and foreign students which would improve their social skills as they could familiarize themselves better with the “American” culture. Participants, including interviewee 13, a male graduate student from the affiliate program also stated that they wanted more intramural activities so they could meet and interact with their peers.

Forty two percent of students interviewed said they needed help with communication skills and public speaking so they could work better with other students and feel more confident and comfortable in group projects and presentations. Supporting 
this argument, participant three, a male graduate student from the affiliate program stated "need more practice to speak in public."

Thirty six percent of students interviewed stated they needed help with industry networking not only to find an internship and a job but also so they could practice their social and networking skills with industry professionals. Participant nine, a female undergraduate student who enrolled independently made this clear when she said “...I was expecting...be more involved in the real world. Involved in the hospitality industry...”

Twenty eight percent of participants stated they wanted help with life skills as well as communication skills. They stated that joining Fraternities and Sororities have helped them not only with their social skills but also with their interview skills and resume more than Career Services has. This argument is supported by participant 11, a female graduate student who enrolled independently as she stated “....after I join the fraternity, the, they help me a lot. They help me...some interview skills.”

Participants also stated in their interviews that they felt they needed an Advisor devoted simply to working with Chinese students, who was familiar with not only the American educational system but with the Chinese culture. Also, that they wanted a peer mentor to guide them not only through their educational experience but also teach them about daily life in America. Finally, participants stated the need for a Frequently Asked Questions booklet about life in America, their educational experience and an Orientation to guide them through the process. 


\section{Theme 4- Work Experience and Legal Issues:}

Seventy one percent of participants stated they were worried about getting a job because they don’t have the necessary work experience. In Chinese culture, people do not begin working until after they are done with their education. In America, people start working as teenagers, especially in the hospitality industry. Therefore, Chinese hospitality students feel they are competing for the same jobs and internships as their American peers but they not only have the language and cultural barrier, they also have the lack of work experience and interview skills to deal with. These students feel the program should include mandatory work experience and networking so they get the necessary help to get jobs when they graduate. They also stated that they enjoy having American Professors who have industry experience and give examples and advice regarding their experience as opposed to simply imparting book knowledge.

Twenty eight percent of students interviewed are worried about getting a work visa to stay in the country when they finish their studies. Most of them don't want to stay in America permanently but they want to get some work experience before going back to China. These students also stated that they needed more guidance from Career Services not only on how to create a proper resume but also on interview skills and the necessary steps to find an internship. They feel internships are very important for them to get experience but they don't know the steps to find the right internship for them.

Twenty one percent of participants worry that their English comprehension and language skills are not good enough for them to get an internship or a job. 


\section{Summary}

This study sought to understand the learning experiences of Chinese hospitality students at a major university in the United States. After the interviews were completed and the information transcribed, coded and analyzed, several patterns began to emerge. One noticeable theme was the concept of students having difficulty speaking and understanding English and not feeling confident enough to speak in class or work in groups with American students because they feel they need more assistance learning English both before coming to the United States and while they are here studying.

The second emerging theme was the perception that the value of their education is being devalued because of the saturation of Chinese students in the program, therefore not permitting them to communicate and interact with a diverse student body population, hurting their chances to really learn multicultural skills both in business and personally. As noted earlier, seventy one percent of participants reported that there is a saturation of Chinese hospitality students and that is hindering their education because based on their culture, they cannot speak freely when there are other Chinese students around for fear of saying the wrong thing, at the same time, not being able to communicate with American students because they lack the preparation needed to feel comfortable around them.

The third emerging theme was the need for assistance with social and communication skills for Chinese hospitality students. As previously stated, fifty seven percent of participants stated the need for help with their social skills in the form of an "English corner" so they could practice their English and interact with American students so they could also learn about life in the United States and ways to make their life more practical, as they noted by having a peer mentor to guide them through the process. 
Lastly, the theme of work experience and legal issues was a very important theme with most of the participants as they feel they not only do not have the necessary work experience to get a job or an internship while they are in the United States, they also do not feel they are getting enough help from Career Services in order to help them get the job they desire. 


\section{CHAPTER FIVE}

\section{CONCLUSIONS AND IMPLICATIONS}

The purpose of this study was to investigate and compare the learning experience of Chinese hospitality students in a 4-year program at a U.S. institution. It allowed Chinese hospitality management students to talk about their perceived learning experiences while in a 4-year program in order for the researcher to evaluate the reoccurring themes regarding their education which could be translated into creating a curriculum that would help bridge the gap between Chinese and American education. This study used a qualitative approach with grounded theory and comparative analysis in the form of interview questions. The following chapter discussed the findings of this study as well as recommendations and suggestions for future research.

\section{Study Findings}

The main themes and categories that emerged through the in-depth interviews were the following: Language, Value of Education, Social Skills and Work Experience/Legal Issues. The researcher's findings are in line with the previous literature regarding the learning experiences of Chinese students in the U.S. Previous studies such as the one from Guang, "Buddhist impact on Chinese culture" talked about how Chinese major religions "emphasize unity” and deal with the idea of doing good for the community, not for the individual. There is no real concept of individual responsibility the way it exists in the Western world (Guang, 2013, 306). This study supports the researcher's findings in this study because many of the interview participants stated they disliked talking in class for fear of either shaming other Chinese students by saying the "wrong" answer or shaming their culture as a whole. An example of this is participant 
nine, a female undergraduate student who enrolled independently. She stated that “...sometimes we want to talk but...we're just afraid...our English is not that good...people may feel difficult to understand what we are talking about. It’s just sometimes, it's like a invisible pressure on us.” Another study that agrees with our findings is that of Lin, Ho \& Lin, "Confucian and Taoist work values: An exploratory study of the Chinese transformational leadership behavior.” This study agrees with our findings regarding interviewees feeling like they are trapped with societal and cultural constraints when it comes to speaking up in class, working in groups and living in the U.S., Lin explains that it is difficult for Chinese to be competitive and act independently because they are used to acting for the benefit of their communities and societies instead of their individual benefit, (Lin, Ho \& Lin, 2013, p 97).

Many participants spoke about the shame of talking in class which also corresponds to other studies in our literature review. One of those studies was the one by Holmes, "Negotiating differences in learning and intercultural communication: Ethnic Chinese students in a New Zealand university.” This study talks about the different teaching models in China and the Western world by talking once again about a "social context that promotes obedience and discourages creativity” (Holmes, 2004), which makes it difficult for Chinese students to be critical thinkers when they are used to an obedience model. Because of this major difference the interview participants said they liked American professors they were more "open and available” than Chinese professors but they had difficulty working in groups and participating in class because the concept of critical thinking was new to them as Grasha stated in "The Dynamics of One-on-One Teaching", Chinese professors are closely related to either the "Expert" or the "Formal 
Authority" teaching models, both of which are based on "teacher centered learning", which amount to lectures, memorization and exams, (Durkin, 2011). This makes Chinese hospitality students feel uncomfortable with critical thinking and participation because they are simply not used to it. Participant seven, a female graduate student who enrolled independently stated that “...American professor are more willing to spend the time with you. But in China, the Chinese professor, actually we don't talk after class.”

Lastly, another major finding that agrees with the previous literature is the fear that Chinese hospitality students feel while looking for an interview or a job while they are in the U.S. because as Huang states in "Transitioning challenges faced by Chinese graduate students”, Chinese students in the U.S. are not only in a foreign country, they are also dealing with "a lack of work experiences and career development opportunities”, especially because their American classmates have usually been in the job market for years, even if not in their desired field (Huang, 2012, 142).

\section{Implications}

Based on the interview responses and all the available current literature, it is the researcher's conclusion that in order to better prepare Chinese hospitality students in a 4year program in the U.S. be successful, the following changes must be made:

1. English courses, specifically a critical thinking course should be required from all Chinese hospitality students either before they come to study in the U.S. or during their first semester. This will not only help them understand the language better 
and be better prepared for their classes but it will give them the confidence to work in groups and live in the U.S.

2. A peer mentor to help students navigate not only life in the U.S. but also adapt to different teaching methods, educational goals and resources as well as help them adapt to American society so they don't feel they have to live in a Chinese "bubble.” It would also be helpful for them to have a FAQ booklet to help them deal with common problems in their education or their life in America.

3. An advisor who not only knows and understands Chinese culture, but also Chinese education and is able to help students transition from one educational background to the other.

4. More social activities and an "English corner" to help Chinse students interact with American students, which they are desperately asking for.

5. Finally, Chinese students must be made aware of the amount of Chinese nationals already in the program and enrolling in the program so they don't feel blindsided when they see the large amount of Chinese students that are already enrolled in the program.

\section{Limitations and Recommendations for Future Study}

Although the research for this study was carefully prepared, there were some limitations. This study was limited to students from a single Department in one university, therefore, the findings might not represent Chinese hospitality students as a whole because of the small population sampled. The interviews were conducted in English, which could present problems with interpretation and because participation was 
voluntary and data was self-reported the researcher cannot verify the complete accuracy of the statements provided. Data collection was restricted to participants who chose to partake in the interviews. It was also limited by time as interviews were conducted over a two week period.

Based on the findings, the researcher recommendations for future study are to do a longitudinal study to see not only how long it takes Chinese students to adapt to life in America but also to the Western teaching methodology and how their confidence and social skills are affected because of it. The benefit of a longitudinal study is that changes in the target population can be measured throughout long periods of time so the researcher can actually measure what it was that made those changes occur, as opposed to this qualitative study that only measured results at a specific point in time. 


\section{REFERENCES}

Clarke, J. (2010). Student Centered teaching methods in a Chinese setting. Nurse Education Today, 30(1), 15; 15-19; 19.

Feng, X. (2009). On American and Chinese higher education. Asian Social Science, 4(6).

Glaser, B. G, \& Strauss, A. L. (1967). The discovery of grounded theory: Strategies for qualitative research. Chicago, Aldine.138.

Guang, X. (2013). Buddhist impact on Chinese culture. Asian Philosophy, 23(4), 305; 305-322; 322.

Ho, R. (2010). Assessment of Chinese students' experience with foreign faculty: A case study from a Chinese university. Journal of Teaching in International Business, 21(3), 156; 156-177; 177.

Holmes, P. (2004). Negotiating differences in learning and intercultural communication: Ethnic Chinese students in a New Zealand university. Business Communication Quarterly, 67(3), 294-307.

Huang, Y. (2012). Transitioning challenges faced by Chinese graduate students. Adult Learning, 23(3), 138-147.

Leung, D. Y. P., Ginns, P., \& Kember, D. (2008). Examining the cultural specificity of approaches to learning in universities in Hong Kong and Sydney. Journal of CrossCultural Psychology, 39(3), 251-266.

Lin, L. (2013). Confucian and Taoist work values: An exploratory study of the Chinese transformational leadership behavior. Journal of Business Ethics, 113(1), 91; 91-103; 103.

Lincoln, Y.S.; Guba, E.G. (1985). Naturalistic Inquiry. Sage Publications.

Nield, K. (2007). Understanding the Chinese learner: A case study exploration of the notion of the Hong Kong Chinese learner as a rote or strategic learner. The Journal of Hospitality, Leisure, Sport \& Tourism Education, 6(1), 39.

Thakkar, D. (2011). Social and cultural contexts of Chinese learners: Teaching strategies for American educators. Multicultural Education (San Francisco, Calif.), 19(1), 5154. 
Trigwell, K. (2013). Evoked prior learning experience and approach to learning as predictors of academic achievement. British Journal of Educational Psychology, 83(3), 363; 363-378; 378.

Wang, R. (2012). Chinese culture and its potential influence on entrepreneurship. International Business Research (Toronto), 5(10)

Webster, B. J. (2009). Undergraduates' learning experience and learning process:

Quantitative evidence from the east. Higher Education, 58(3), 375; 375-386; 386.

Wu, S. (2007). The effect of culture on perspective taking, (author abstract).

Psychological Science, 18(7), 600. 


\section{APPENDIX A}

Research Questions

1. What is Chinese students perception of their learning experience?

2. What do Chinese students feel is missing from their learning experience?

3. What is Chinese students perception of their American counterparts?

Interview Questions:

1. What is your perception of your learning experience?

2. Tell me about your ideal learning environment.

3. What do you feel is missing from your education?

4. How do you feel about working with American students?

5. How comfortable are you working in groups and speaking in class?

6. How comfortable are you with American Professors?

7. What are your major concerns regarding your education?

8. What is your motivation for learning?

9. Is there anything else you would like me to know regarding your learning experience? 


\begin{abstract}
APPENDIX B
Informed Consent:

Hospitality Education Assessment: A case study on the learning experience of Chinese students studying in the United States
\end{abstract}

\title{
Rossy Ambe-Cohen
}

\section{Project Description:}

The purpose of this study is to investigate and compare the learning experience of Chinese Hospitality students at a 4-year program in a U.S. institution in order to create a curriculum that helps bridge the gap between Chinese and American education. This qualitative study will collect interview data from Chinese Hospitality students to learn about their views on their perceived learning and the quality of their learning and to examine any issues that may emerge from those answers.

\section{Procedure and Risks:}

We would like to record the interview, if you are willing, and use the tapes to write our materials. We will record the interview only with your written consent, and will ask that no personal identifiers be used during the interview, to ensure your anonymity. Please feel free to say as much or as little as you want. You can decide not to answer any question, or to stop the interview any time you want. The tapes and transcripts will become the property of project.

If you so choose, the recordings and recording-transcripts (or copy of notes taken) will be kept anonymous, without any reference to your identity, and your identity will be concealed in any reports written from the interviews.

There are no known risks associated with participation in the study.

\section{Benefits:}

It is hoped that the results of this study will benefit the Hospitality program at a 4-year university in the U.S. by creating a comprehensive curriculum that takes into account the learning experiences of their large Chinese student population.

\section{Cost Compensation:}

Participation in this study will involve no costs or payments to you.

\section{Confidentiality:}

All information collected during the study period will be kept strictly confidential until such time as you sign a release waiver. No publications or reports from this project will include identifying information on any participant without your signed permission, and after your review of the materials. If you agree to join this study, please sign your name on the following page 
I, , agree to be interviewed for the project entitled Hospitality Education Assessment: A case study on the learning experience of Chinese students studying in the United States which is being produced by Rossy AmbeCohen.

I certify that I have been told of the confidentiality of information collected for this project and the anonymity of my participation; that I have been given satisfactory answers to my inquiries concerning project procedures and other matters; and that I have been advised that I am free to withdraw my consent and to discontinue participation in the project or activity at any time without prejudice.

I agree to participate in one or more electronically recorded interviews for this project. I understand that such interviews and related materials will be kept completely anonymous, and that the results of this study may be published in an academic journal or book.

I agree that any information obtained from this research may be used in any way thought best for this study.

Date

Signature of Interviewee

If you cannot obtain satisfactory answers to your questions or have comments or complaints about your treatment in this study, contact:

Rossy Ambe-Cohen

Cc: signed copy to interview. 


\section{LEARNING EXPERIENCE OF CHINESE STUDENTS}

\section{Final Consent Form}

Hospitality Education Assessment: A case study on the learning experience of Chinese students studying in the United States

Dear Participant:

This form gives us final authorization to use material from your interview in A draft of these materials should have been presented to you for your review, correction, or modification. You may grant use rights for this draft "as is," or with the modifications you specify, if any. See "Conditions" at the bottom of the form

I, hereby grant the right to use information from recordings and or notes taken in interviews of me, to Rossy AmbeCohen, and as presented to me as a draft copy. I understand that the interview records will be kept by the interviewer and the project, and that the information contained in the interviews may be used in materials to be made available to the general public.

Date:

Signature of Interviewee

Date:

Signature of Interviewer

The following conditions limit the release of information, as agreed between the interviewer and the interviewee:

None needed

Material may be released once corrections I specified have been made 